\title{
Synthesis of Platinum Nanostructures Using Seeding Method
}

\author{
Sang-Beom Han, You-Jung Song, Jong-Min Lee, Jy-Yeon Kim, Do-Hyung Kim, ${ }^{\dagger}$ and Kyung-Won Park \\ Department of Chemical and Enwironmental Engineering, Soongsil Lniversitw, Seoul 156-743, Korea \\ ${ }^{*}$ E-mail: kiparkiâssuack" \\ -Green Growth Laboratory, Korea Electric Power Research Institute, Daejeon 305-760, Korea \\ Received April 28, 2009, Accepted September 1, 2009
}

\begin{abstract}
We report Pt hexapod nanoparticles with $6.4 \sim 9.7 \mathrm{~mm}$ in size by a polyol process in the presence of PVP as a stabilizer and additive as a kinetic controller. The structure and morphology of Pt nanostructures are confirmed by field-emission transmission electron microscopy. The morphological control over platinum nanoparticles is achieved by varying the amount of seeds in the polyol process, where platinum precursor is reduced by ethylene glycol to form $\mathrm{Pt}$ nanoparticle at $150^{\circ} \mathrm{C}$. As volume ratio between precursor-solution and seed-solution is increased from 10 to 50 , the shape of Pt nanostructures is evolved from small seeds to tripod and hexapod. In addition, the size-controlled platinum hexapod nanostructures are successfully obtained using seeding method.
\end{abstract}

Key Words: Platinum, Hexapod, Shape control. Seeding method

\section{Introduction}

Catalytic activity of platimum for energy conversion. especially, at low temperatures makes this metal electrocatalyst ideal for use as electrodes in direct alcohol fuel cells (DAFCs). dye sensitized solar cells (DSSC) and microbial fuel cells (MFCs) ${ }^{1.4}$ Single crystalline platinum surfaces. such as low index (111). (100). and (110) stnictures. have been stidied as idealized platforns for electrocataly tic reactions because the surface atomic arrangement affects the electrochemical properties. The exposed face of catalysts among them could be selected by modulating the growth rate of metal nanostnictures. ${ }^{5-8}$ It is most likely that a nanocrystal structure with a particular face is selectively formed by slow growth rate during the process with chemical environments. Especially, it has been reported that shapes of nanoparticles such as cube. octahedron tetrahedron. cuboctahedron shows specific crystal planes such as $\{111\}$ and/or $\{100\}$. $^{6.9 .11}$

In the Wulff facets argument or Gibbs-Curie-Wulff theorem. the shape of a crystal is determined by the relative specific surface energy of each face of the crystal. In the crystal structure. the equilibrium shape is the one that minimizes the surface Gibbs energy. ${ }^{1-13}$ If surface energies are deternined through various facets. the equilibrium shape can be expected. When this concept is translated into relative growth rates of the facets, the most stable facets would have lower growth rates and be the most developed ones in the overall equilibrium shape. Fast-growing facets will eventually disappear during growth in a chemical process. resulting in a crystal terminated by slower-growing facets. Once the facets form. fast-growing facets will persist. replacing the initial highenergy facet.

Herein. we report that morphology and size of Pt nanostructures could be controlled by means of polyol method. The shape of Pt nanoparticles was evolved from small seeds to tripod and hexapod as a function of volume ratio between precursor-solution and seed-solution. In addition, the size-controlled platinum hexapod ninostructures were formed using seeding method. The morphology, structure. and size distribution of the nanoparticles were elaborately characterized by field-emission transmission electron microscopy.

\section{Expelimental}

One step method. A solution of $1 \mathrm{mM} \mathrm{H} \mathrm{H}_{2} \mathrm{PtCl}_{6 .} .10 \mu \mathrm{M}$ $\mathrm{NaNO}_{3}$. and $20 \mu \mathrm{M} \mathrm{FeCl}_{3}$ was prepared in $50 \mathrm{~mL}$ of ethylene glycol (EG). to which we added $50 \mathrm{mg}$ poly(vinyl pyrrolidone) (PVP. MW $=29.000$ ). All chemicals used were of analytical grade. The change of color in the solution was observed as raised by $1{ }^{\circ} \mathrm{C} / \mathrm{min}$. At $180^{\circ} \mathrm{C}$. the solution became dark brown from yellow and was kept for $1 \mathrm{~h}$ until $\mathrm{H}_{2} \mathrm{PtCl}_{6}$ was completely reduced by $\mathrm{EG}$. After the reaction for nanoparticle preparation. the colloid solution was cooled at room temperature. washed by acetone, and then precipitated using centrifuge.

Seeding method. To prepare seed colloid solution $10 \mathrm{mM}$ $\mathrm{H}_{2} \mathrm{PtCl}_{5 .} .100 \mu \mathrm{M} \mathrm{NaNO}{ }_{3} .100 \mathrm{mM} \mathrm{PVP}$ and $200 \mu \mathrm{M} \mathrm{FeCl}_{s}$ were dissolved in $5 \mathrm{~mL}$ of EG. The solution was rapidly added to $45 \mathrm{~mL}$ of ethylene glycol at boiling temperature and then immediately cooled to room temperature resulting in a seed colloid solution. For seeding method. the seed colloid solution was mixed in a precursor-solution consisting of $1 \mathrm{mM} \mathrm{H}_{2} \mathrm{PtCl}_{6}$. $10 \mu \mathrm{M} \mathrm{NaNO} \mathrm{N}_{3} .10 \mathrm{mM} \mathrm{PVP}$ and $20 \mu \mathrm{M} \mathrm{FeCl}_{3}$ in the range of $2 \%$ to $10 \%$. The seed-solutions were heated at $110^{\circ} \mathrm{C}$ and 150 ${ }^{\circ} \mathrm{C}$. respectively. The $2 \%$ seed-solution was heated at $110^{\circ} \mathrm{C}$ for $24 \mathrm{~h}$ and then at $150^{\circ} \mathrm{C}$ for $2 \mathrm{~h}$. In addition, the 2,6 . and $10 \%$ seed-solutions were heated and reacted at $150^{\circ} \mathrm{C}$ for $2 \mathrm{~h}$. After the reaction. the seed-solutions were cooled at room temperature. washed by acetone. and then precipitated using centrifuge.

The morphology. structure, and size distribution of the nanostructures were characterized by field-emission transmission electron nucroscopy (FE-TEM) using a Philips F20 system operating at $200 \mathrm{kV}$. TEM samples were prepared by placing a drop of nanoparticle suspension dispersed in an ethanol on a carbon-coated copper grid. 


\section{Results and Discussion}

Fig. I shows TEM image of Pt nanostnictures obtained by means of one-step method. It was observed that almost all the Pt nanostructures consisted of hexapod slape $(\sim 95 \%)$ oriented along the $\langle 111\rangle$ axis with the comers pointing toward the $<100>$ directions. However. in the case of one-step method. the synthetic condition for the hexapod nanostructure should be elaborately controlled because of the experimental sensitivity in the chemical process.

Fig. 2A and B show Pt nano-seeds prepared by means of polyol process at boiling temperature of EG. The spherical nanoparticles of $3 \sim 4 \mathrm{~nm}$ in size were used as seeds for seeding method to synthesize Pt multipod nanostructures. Fig. $2 \mathrm{C}$ and $\mathrm{D}$ show TEM images of Pt nanostnictures synthesized using seeding method in $2 \%$ seed-solution consisting of $1 \mathrm{~mL}$ seed colloid solution and $50 \mathrm{~mL}$ precursor-solution at $110^{\circ} \mathrm{C}$ for $24 \mathrm{~h}$. In the one-step method. as already shown in the Fig. 1 , the Pt hexapod nanostructures were formed at $180^{\circ} \mathrm{C}$ higher than $110^{\circ} \mathrm{C}$. However. in the case of seeding method. the formation of hexapod nanostructures was achieved at relatively lower temperature of $110^{\circ} \mathrm{C}$ than $180^{\circ} \mathrm{C}$. This implies that heterogeneous nucleation for hexapod formation via seeding method is thermodynamically favourable compared to homogeneous nucleation via one-step method. ${ }^{1 \dagger}$ As shown in the Fig. $2 \mathrm{C}$ and $\mathrm{D}$. the average size of hexapod nanostructures is $\sim 10 \mathrm{~nm}$. The nano-seeds seem to be partially grown into the hexapod manoparticles. However, although the seeding method is systematically favourable. the spherical seeds seem to be partially grown into hexapod at $110{ }^{\circ} \mathrm{C}$. For the complete reaction of $2 \%$ seeds-solution. the solution was reheated at $150{ }^{\circ} \mathrm{C}$ and kept for $2 \mathrm{~h}$. As shown in Fig. 2E and F. small spherical seeds disappeared with overgrowth of hexapod

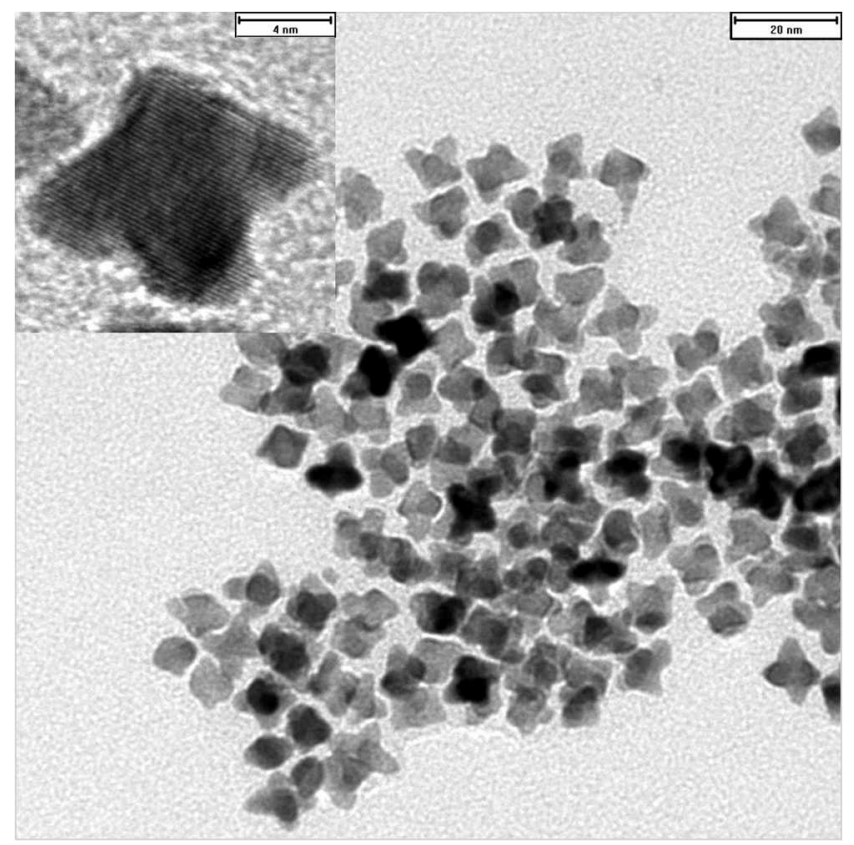

Figure 1. TEM image of Pt nanostructures obtained by one-step method at $180^{\circ} \mathrm{C}$. nanostructures. Thus. it is considered that in the seeding method the reaction at $150{ }^{\circ} \mathrm{C}$ is favourable for hexapod growth of nano-seeds

Fig. 3 shows TEM images of Pt nanostructures synthesized by seeding method with different ratios between seeds-solution and precursor-solution $(2,6$, and $10 \%)$ at $150{ }^{\circ} \mathrm{C}$ for $2 \mathrm{~h}$. They clearly indicate complete reaction without any spherical seed. Fig. 3 A shows TEM image of Pt nanostructures formed in 2\% seeds-solution containing $1 \mathrm{~mL}$ seed colloid solution and 50 $\mathrm{mL}$ precursor-solution. In the case. the Pt nanostructures consist of $\sim 95 \%$ hexapod with uniform average size of $\sim 9.65$ $\mathrm{nm}$. It is found that the hexapod nanostructure shows octahedron shape grown to edge and comer. Fig. 3B shows TEM image of $\mathrm{Pt}$ nanostructures fonmed in $6 \%$ seeds-solution containing $3 \mathrm{~mL}$ seed colloid solution and $50 \mathrm{~mL}$ precursorsolution. In the case of $6 \%$ seeds-solution, the Pt nanostructures consist of $63 \%$ hexapod of $\sim 7.25 \mathrm{~nm}$ and $37 \%$ tripod of $\sim 10.58 \mathrm{~nm}$. The hexapod structures became smaller in size compared to those synthesized in $2 \%$ seeds-solution. In particular. it is interesting that although no formation of tripod occurs at $2 \%$ seeds-solution. the tripod nanostructure is

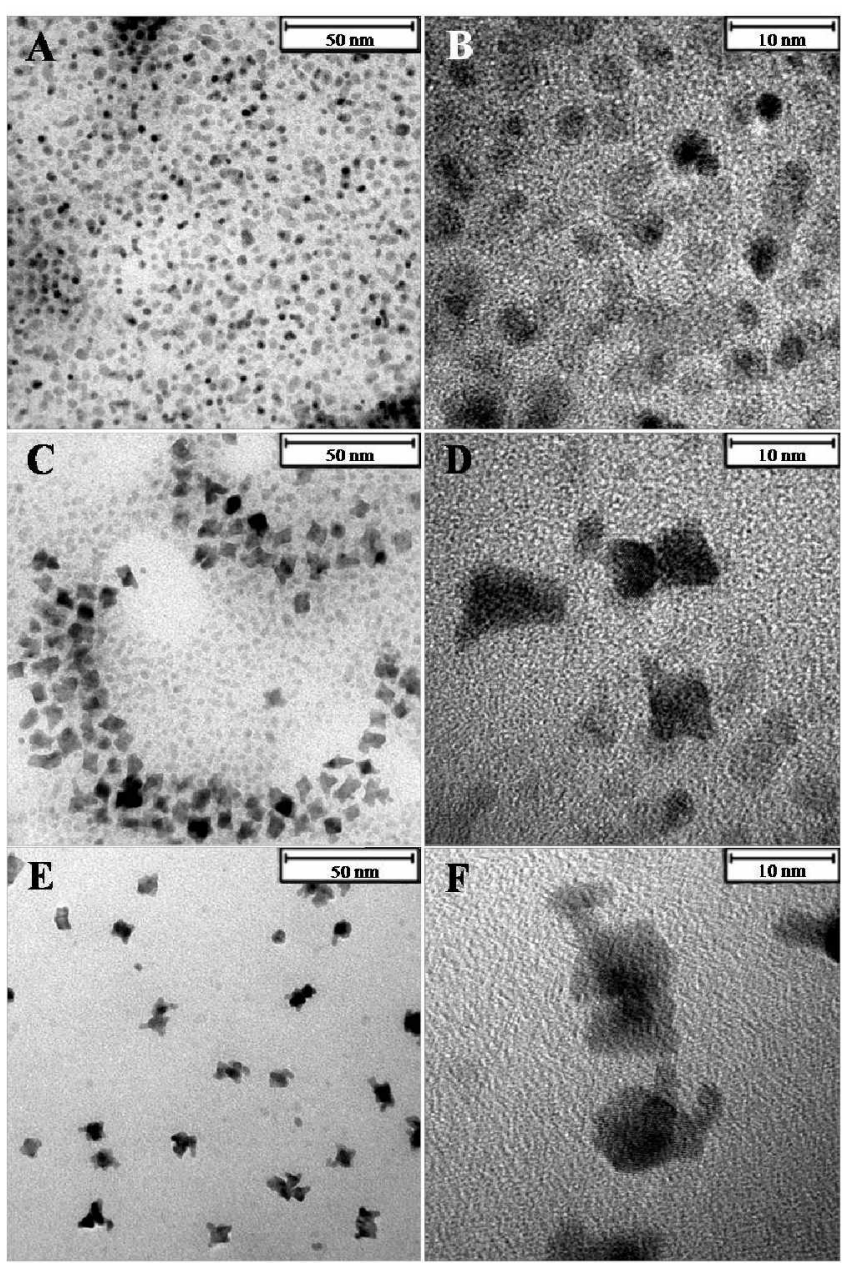

Figure 2. TEM images of Pt nano-seeds prepared by means of polyol process at boiling temperature of $\mathrm{EG}$ (A \& B), Pt nanostructures synthesized using seeding method in $2 \%$ seeds-solution at $110^{\circ} \mathrm{C}$ for $24 \mathrm{~h}(\mathrm{C} \& \mathrm{D})$, and Pt nanostructures reheated at $150^{\circ} \mathrm{C}$ for $2 \mathrm{~h}(\mathrm{E} \& \mathrm{~F})$. 


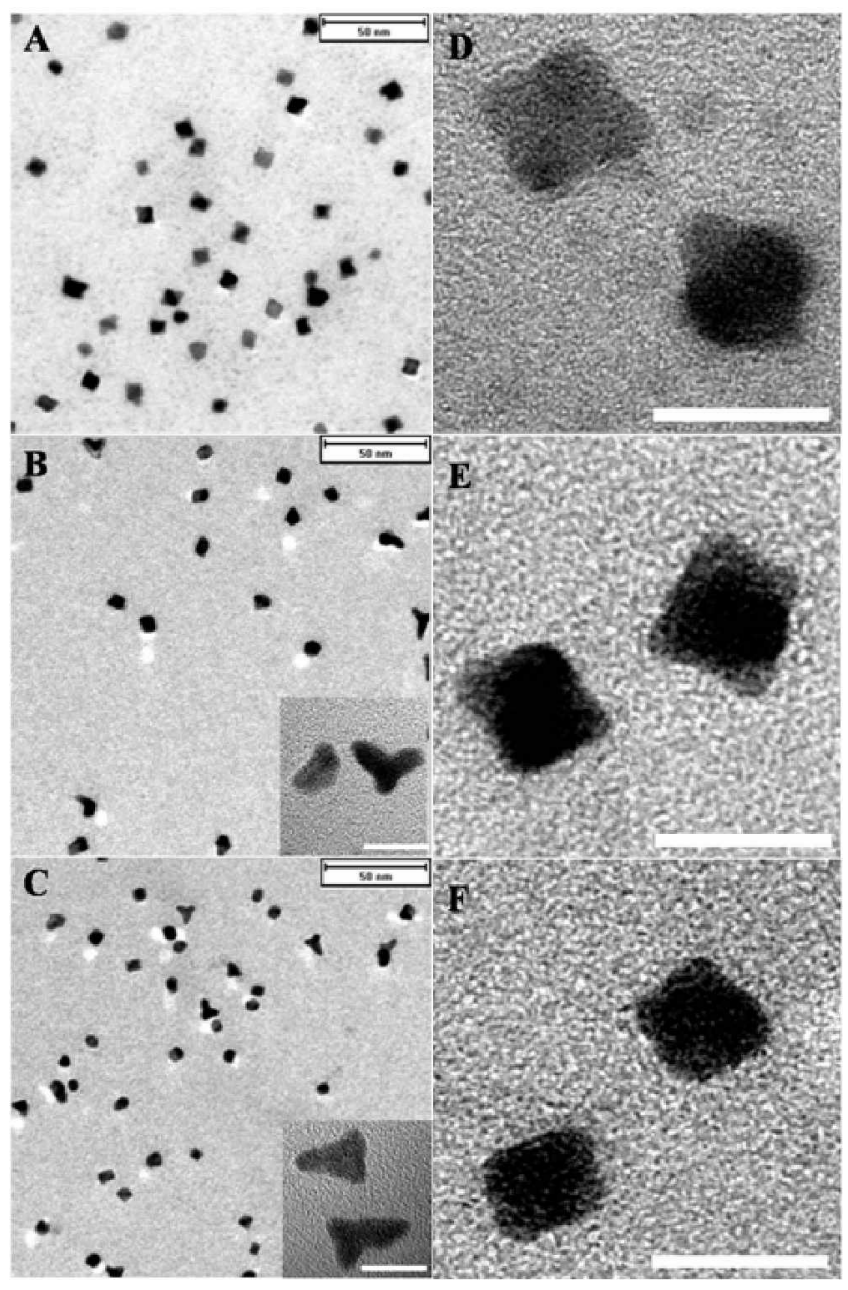

Figure 3. TEM images of Pt nanostnuctures synthesized by seeding method with (A) $2 \%$, (B) $6 \%$, (C) $10 \%$ seeds-solution at $150^{\circ} \mathrm{C}$ for $2 \mathrm{~h}$. High-resolution TEM images Pt nanostructures synthesized through (L) $2 \%$ : (E) $6 \%$, ( 1 ) $10 \%$ seeds-solution (L) F, Scale bar $10 \mathrm{~mm}$ ).

formed in $6 \%$ seeds-solution. Fig. 3C shows TEM image of Pt nanostnictures fonmed in $10 \%$ seeds-solution containing 5 $\mathrm{mL}$ seed colloid solution and $50 \mathrm{~mL}$ precursor-solution. In the case of $10 \%$ seeds-solution, the Pt nanostructures consist of $69 \%$ hexapod of $\sim 6.39 \mathrm{~nm}$ and $31 \%$ tripod of $\sim 7.51 \mathrm{~nm}$. Maksimuk et al. also observed platinum tripod nanostructures with dominant $\{111\}$ planes. ${ }^{15}$ However although the tripod nanostructures are relatively metastable in comparison with hexapod nanostructures. the increased amount of seeds could result in fast growth rate and thus formation of metastable tripod structures. In the case of $10 \%$ seeds-solution, the hexapod structures became smaller in size compared to those synthe- sized in $2 \%$ and $6 \%$ seeds-solutions. Thus, using seeding method as a function of ratio of seeds-solution to precursorsolution. we could obtain size-controlled dominant hexapod nanostructures. smaller than those previously reported.

\section{Conclusion}

Platinum hexapod nanostructures were synthesized by means of polyol reaction in the presence of PVP and additives. The morphology of platinum nanostructures was controlled by varying the amount of seeds added to a polyol process. With increasing ratio of seeds-solution to precursorsolution. the shape of Pt nanostructures was doninantly evolved from sphere to hexapod. We could obtain size-controlled hexapod nanostructures as a function of ratio of seeds-solution to precursor-solution

Aclonowledgments. This work is the outcome of a Manpower Development Program for Energy \& Resources supported by the Ministry of Knowledge and Economy (MKE) and was supported by BioGreen 21 of Korea Rural Development Administration.

\section{Refeiences}

1. Larminie. T.: Dicks, A. Fuel Cell Systems Explained 2000, 133. 2. Gratzel M Nature 2006, $11+338$

3. Kim, S.-S.: Nah, Y.-C.: Noh, Y.-Y.: To, T.; Kim, D.-Y. Electrochim. Acta 2006, 51,3814 .

4. Markovic, N. M.; Gasteiger, H. A.; Ross, P. N. J. Phws. 1995, 99 , 3411 .

5. Seo, M.; Yun, Y,; Lee, J.: Tak, Y. J. Power Sources 2006, 159. 59

6. Han, S.-B.: Song, Y.-T.: Lee, J-M.: Kim, J-Y.: Park, K.-W. Electrochent Connm $2008,10,1044$

7. Wang, C.; Dimon, H.: Lee, Y.; Kim, J.; Sun, S. J. Am. Chent Soc. 2007, 129, 6974.

8. Alumad, T. S.; Wang, Z. L.; Green, T. C.: Henglein, A.; El-Sayed, M. A. Science 1996.272.1924.

9. Tá, A. R.: Sinsermsuksakul, P.; Yang, P. Angew.Chem. 2006, 118,4713

10. Song, H.; Kim, F.; Connor, S.; Somorjai, G. A.; and Yang, P. T. Phys. Chem. B 2005, 109, 188 .

11. Jun. Y.-W.: Choi, I-S.: Cheon. I. Angew. Chem. $2006,118$. 3492 .

12. Mullin, I. W. Cnstallization, 4th ed: Elsevier: Oxford, 2001; 216.

13. Wulfi, G. Z. Kristallogr: 1901, 34, 449

14. Fievet, F. J.; Lagier, P.; Blin, B.; Beaudoin, B.; Figlarz, M. Solid State lonics $1989,198,32$

15. Maksimuk, S.: Teng, X.: Yang. H. J. Phs Chem C 2007, 111. 14312

16. Herricks, T: Chen, T.; Xia, Y. Nano Letters 2004 + 2367

17. Song, H.; Kim, F, Connor, S.; Somorjai, G. A.; Yang, P. J. Phw. Chem. B 2005, 109, 188

18. Tá. A. R.: Habas. S.: Yang. P. Small 2008, 4,310 . 